\title{
Association between Malignant Disease in Children and Maternal Virus Infections
}

\author{
J. F. BITHELL， G. J. DRAPER， P. D. GORBACH
}

British Medical fournal, 1973, 1, 706-708

\section{Summary}

The possibility of an association between virus infections during pregnancy and subsequent malignant disease in the child has been investigated using retrospective data from the Oxford Survey of Childhood Cancers. Such an association appears to exist for influenza, chickenpox, and possibly rubella. For influenza and rubella the estimated risk is small; the data do not permit an estimate to be made directly in the case of chickenpox. It is suggested that there may be a specific association between maternal chickenpox and tumours of the nervous system.

It is important to emphasize that, even if the relative risk associated with these viruses is fairly large, the number of cases of childhood cancer and leukaemia actually attributable to them is probably very small.

\section{Introduction}

Much interest has been focused recently on the possible association between virus infections in pregnancy and malignant disease in the child. Fedrick and Alberman (1972), when reporting the results of the 1958 Perinatal Mortality study, found an unexpectedly large number of children developing leukaemia among those whose mothers had had influenza during pregnancy. They also analysed population data and found an association between influenza rates in the population of working women-as measured by sickness absence returnsand subsequent deaths of children born in the relevant periods.

Such relations can be examined by using data from the Oxford Survey of Childhood Cancers. This study covers childhood deaths from cancer and leukaemia in Britain since 1953. Originally, children dying under the age of 10 were included, but this age range was later extended to 16. Informa-

Department of Social Medicine, Oxford University, Oxford OX1 3QN

J. F. BITHELL, M.A., D.PHIL., Medical Statistician

G. J. DRAPER,

P. D. GORBACH, B.A., Research Officer

tion is obtained from various sources. In particular, interviews with the mothers provided details of their pregnancy illnesses which were corroborated by reference to antenatal records whenever possible. Control children, individually matched for sex and date of birth, were selected from the birth registers of the districts of residence of the index children and their parents were visited by the same interviewers.

Stewart et al. (1958) reported a fuller account of the methods used and reviewed the results up to that time, showing that virus infections were implicated by a contrast of 10 cases of children with malignant disease to one control. The present analysis brings these findings up to date and is based on interviews relating to over 9,000 pairs of cases and matched control children.

\section{Results}

The numbers of cases of children developing malignant disease whose mothers reported having contracted a virus infection during the relevant pregnancy are given in table I. These figures are subdivided according to whether the child developed leukaemia, some other disease of lymphatic tissue (I.C.D. 200209), or some other tumour. The totals are then compared with the numbers of matched control (healthy) children whose mothers reported the same disease.

\section{INFLUENZA}

It will be seen that there are one and a half times as many mothers of cases as of controls reporting influenza, giving an estimated relative risk of 1.52 , with $95 \%$ confidence limits of $1 \cdot 11$ to $2 \cdot 14$, calculated by the method of Miettinen (1970). Although this estimate is appreciably less than the five-fold increase in risk found by Fedrick and Alberman (1972), it is nevertheless significant $\left(\chi^{2}=6.44,1\right.$ D.F.).

It is also shown in table I that the affected children whose mothers had had influenza had tumours which were typical of the survey as a whole, another result in contrast to the findings of Fedrick and Alberman, where the principal excess was found among mothers of children developing acute lymphatic leukaemia.

The trimesters mentioned in the influenza histories are shown in table II. It can be seen that more episodes are reported in the

TABLE I -Numbers of Affected Children (by Tumour) and Matched Controls where Mothers Reported Virus Infections in Pregnancy (Britain, Deaths 1953-67)

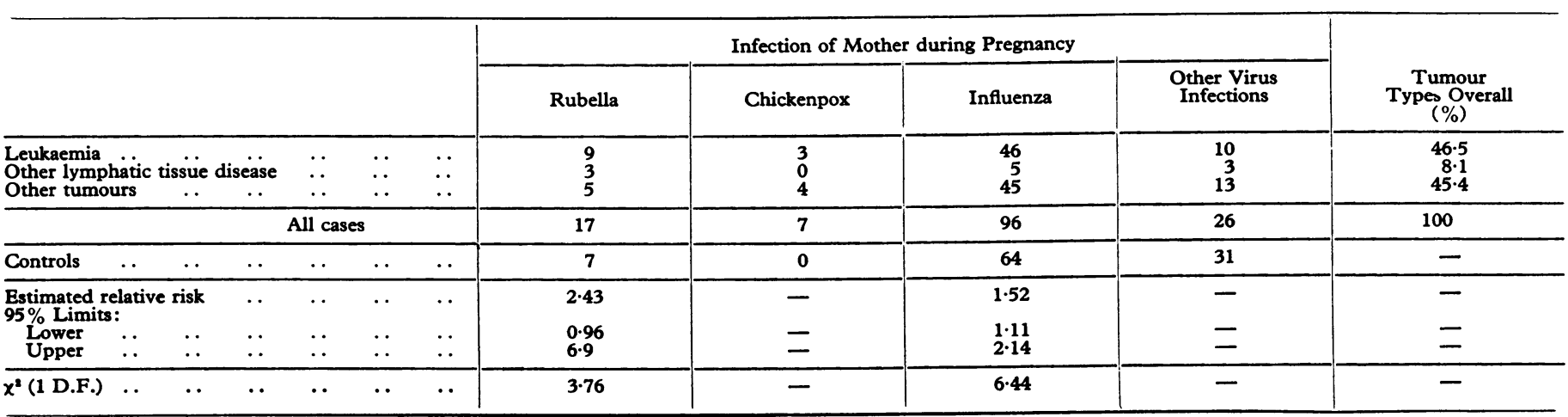


TABLE II-Trimester of Occurrence of Influenza for Mothers of Cases and Controls

\begin{tabular}{|c|c|c|c|c|c|}
\hline & \multicolumn{4}{|c|}{ Trimester } & \multirow[t]{2}{*}{ Total } \\
\hline & 1 & 2 & 3 & N.R. & \\
\hline $\begin{array}{l}\text { Cases: } \\
\quad \text { Leukaemia } \ldots \text {. } \ldots \\
\text { Other lymphatic tissue disease } \\
\text { Other tumours } \ldots\end{array}$ & $\begin{array}{r}8 \\
1 \\
10\end{array}$ & $\begin{array}{r}16 \\
3 \\
10\end{array}$ & $\begin{array}{r}16 \\
0 \\
18\end{array}$ & $\begin{array}{l}6 \\
1 \\
7\end{array}$ & $\begin{array}{r}46 \\
5 \\
45\end{array}$ \\
\hline All tumours & 19 & 29 & 34 & 14 & 96 \\
\hline Controls & 6 & 24 & 27 & 7 & 64 \\
\hline
\end{tabular}

N.R. = Not recorded.

later stages of pregnancy. This might be indicative of differential susceptibility to illness at different stages of pregnancy (Purtilo et al., 1972), but there may well be an appreciable memory effect, events later in pregnancy being more easily recalled. We return below to the question of memory and under-reporting. In any case there is no evidence of a difference between trimesters in the effect of the virus on the fetus.

In an attempt to concentrate attention on the occurrences of influenza which were of recognizable viral types, the affected cases and controls were classified according to whether they occurred during known epidemics, the latter being defined by reference to influenza mortality statistics and listed in table III. (The information on virus types in most of these periods is given in Stuart-Harris (1965)). The problem of dating events during preg nancy is not easy and though we adhered to welldefined and consistent rules it was thought to be desirable to include one month before and one month after the periods shown in table III when defining the dates at which there were high levels of influenza.

TABLE III-Periods of High Influenza Mortality Regarded as Defining Epidemics of Known Virus Types

\begin{tabular}{llc|l|lrr} 
Months & \multicolumn{2}{c|}{ Virus Type } & Months & \multicolumn{3}{c}{ Virus Type } \\
December 1948-April 1949 & $\ldots$ & $A^{\prime}$ & February 1959-April 1959 & $\ldots$ & A2/B \\
January 1950-April 1950 & $\ldots$ & B & January 1961-March 1961 & $\ldots$ & A2 \\
December 1950-April 1951 & $\ldots$ & A' & December 1961-February 1962 & B \\
December 1952-April 1953 & $\ldots$ & A1 & February 1963-April 1963 & $\ldots$ & A2 \\
December 1954-April 1955 & $\ldots$ & B & January 1966-March 1966 & $\ldots$ & A2/B
\end{tabular}

Moreover, since most reported episodes of influenza did fall within these brackets, we have treated the 34 pregnancies where the month was not exactly specified as having overlapped a particular period unless the information available-notably the date of birth-rendered this impossible.

The results of this classification after combining contributions from epidemics known to have involved viruses of the three basic types are given in table IV. Although the estimated relative risk for the 1957-8 epidemic is slightly higher, the differences between the various types of epidemic are only slight and are not significant. Nevertheless, the occurrences of influenza outside the defined periods clearly carry no excess risk and their elimination sharpens the overall comparison to 71 cases against 41 controls (including three pairs where both case and control mothers had influenza), giving an estimated relative risk of 1.79 (95\% confidence interval 1.22 to $2 \cdot 74)$.

TABLE IV-Numbers of Affected Children and Controls Whose Mothers Probably had Influenza During the Specified Periods

\begin{tabular}{|c|c|c|c|c|}
\hline & & $\begin{array}{l}\text { No. of } \\
\text { Cases }\end{array}$ & $\begin{array}{l}\text { No. of } \\
\text { Controls }\end{array}$ & Relative Risk \\
\hline 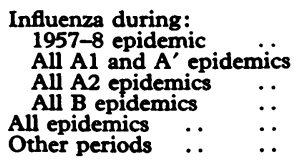 & $\begin{array}{l}\because \\
\because \\
\cdots \\
\cdots\end{array}$ & $\begin{array}{l}27 \\
12 \\
43 \\
23 \\
71 \\
25\end{array}$ & $\begin{array}{r}13 \\
7 \\
27 \\
12 \\
41 \\
23\end{array}$ & $\begin{array}{l}25 / 11=2.27 \\
12 / 7=1.71 \\
40 / 24=1.67 \\
23 / 12=1.92 \\
68 / 38=1.79 \\
25 / 23=1.09\end{array}$ \\
\hline
\end{tabular}

The entries in this table are not mutually exclusive.
CHICKENPOX

Seven mothers of children in the affected group reported chickenpox compared with none in the control group (table I). This rather remarkable finding is highly significant $(P<0.01)$. A list of these seven cases is given in table V, and it will be seen that three of the children developed lymphatic leukaemia. Two others are known to have developed medulloblastomas, while for a third the histology was inconclusive, alternative diagnoses of medulloblastoma and neuroblastoma being suggested. Accepting for the moment that there were three cases of medulloblastoma, the result is remarkable in that the expected number of such tumours among seven cases of malignant disease is only 0.3 . Although the probability of three or more cases of medulloblastoma occurring by chance is consequently quite small (less than 1 in 200), it must be remarked that there was no earlier hypothesis that this tumour might be specifically linked to viral infections. The problem of assessing statistical significance in this situation is far from easy. On the other hand, the result acquires particular interest in the light of the known tendency of the varicella virus to persist in nervous tissue.

TABLE v-Listing of Seven Affected Children Whose Mothers Reported Chickenpox in Pregnancy

\begin{tabular}{|c|c|c|c|c|c|}
\hline Tumour & $\begin{array}{c}\text { Date of } \\
\text { Birth }\end{array}$ & $\begin{array}{c}\text { Age } \\
\text { at Onset }\end{array}$ & $\begin{array}{c}\text { Age } \\
\text { at Death }\end{array}$ & Sex & $\begin{array}{l}\text { Month of } \\
\text { Pregnancy }\end{array}$ \\
\hline 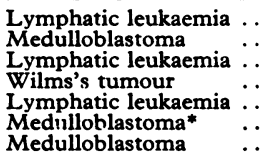 & $\begin{array}{r}3 / 48 \\
12 / 51 \\
12 / 52 \\
10 / 53 \\
5 / 58 \\
4 / 60 \\
8 / 62\end{array}$ & $\begin{array}{l}11 \cdot 0 \\
5 \cdot 7 \\
4 \cdot 2 \\
2 \cdot 10 \\
3 \cdot 9 \\
1 \cdot 5 \\
4 \cdot 2\end{array}$ & $\begin{array}{c}11 \cdot 9 \\
7 \cdot 1 \\
6 \cdot 1 \\
4 \cdot 4 \\
4 \cdot 7 \\
1 \cdot 10 \\
4 \cdot 7\end{array}$ & $\begin{array}{l}\text { M. } \\
\text { M. } \\
\text { F. } \\
\text { M. } \\
\text { M. } \\
\text { F. }\end{array}$ & $\begin{array}{l}\text { 9th } \\
\text { 2nd } \\
5 \text { th } \\
\text { 7th } \\
\text { 7th } \\
\text { 7th } \\
6 \text { th }\end{array}$ \\
\hline
\end{tabular}

*Histology inconclusive (see text).

The ages at onset and death of the seven children are also shown in table V, together with the sex and the month of pregnancy in which the chickenpox was reported to have occurred. Although the latter were derived using the same rules as were used for the influenza cases, they must be regarded as being unreliable and quite likely to be one month wrong at the least

The relative risk associated with an occurrence of chickenpox cannot, of course, be estimated from a case: control ratio of 7:0 and the only possibility of obtaining such an estimate would be to replace the zero by an expected number of affected pregnancies calculated from the results of some other study. It is impossible to use the survey reported by Adelstein and Donovan (1972) for this purpose. On the other hand, calculations based on the number of mothers in the 1958 British Perinatal Mortality survey contracting chickenpox in pregnancy (J. Fedrick, personal communication, 1972) give an expected number of cases in our study of $2 \cdot 18$. There are many methodological differences between the two studies; in particular, that of 1958 covered a risk period of only nine months. However, if we ignore these and the possibility of under-reporting in our study we obtain a tentative relative risk estimate of around 3.7.

\section{OTHER VIRUS INFECTIONS}

Of the other virus infections only rubella shows an appreciable case-control excess-the 17 cases to seven controls gives an estimated relative risk of $2 \cdot 43$, though this just fails to be significantly different from unity at the conventional $5 \%$ level. Other infections reported included mumps (9:10), infectious hepatitis $(7: 8)$, and herpes zoster $(5: 5)$.

\section{Interpretation of Results}

Before concluding from significant case-control comparisons that virus infections are causally implicated in the develop- 
ment of malignant disease it is necessary to examine the biases that might apply to retrospective data such as described in this paper.

Under-reporting clearly affects the apparent incidence of influenza and possibly of other infections; it results from the fact that information is obtained by interviewing the mother of the child who has died, usually some years after the pregnancy. Attempts were made to corroborate the reports by tracing the antenatal clinic records. This proved to be possible for about two-thirds of the mothers in both groups who reported influenza, about half the records containing a specific reference to a virus infection. There were no significant differences in these proportions as between affected children and controls. Although under-reporting reduces the power of the data to detect associations it will introduce no bias provided that mothers in both groups remember equally effectively.

Whether this is so can never be determined for certain, as we cannot eliminate the possibility of a bias resulting from the psychological effects of bereavement. An obvious check, however, is to examine the frequencies of reporting of conditions not thought to be related to malignant disease. These frequencies for three common conditions of pregnancy-namely, toxaemia, anaemia, and bronchitis-are given in table VI. None of these conditions shows a significant case-control excess, and to this extent the figures encourage the belief that reporting of events in pregnancy is reasonably comparable as between affected children and controls.

TABLE VI-Numbers of Traced Cases and Matched Controls in the Oxford Survey of Childhood Cancers whose Mothers Reported Various Pregnancy Conditions

\begin{tabular}{|c|c|c|c|c|c|c|c|}
\hline & & & & Toxaemia & Anaemia & Bronchitis & All Pairs \\
\hline $\begin{array}{l}\text { Cases } \\
\text { Controls .. } \\
\text { Cases/controls }\end{array}$ & $\cdots$ & 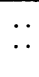 & $\begin{array}{l}\because \\
\because\end{array}$ & $\begin{array}{l}938 \\
893 \\
1.05\end{array}$ & $\begin{array}{l}713 \\
708 \\
1.01\end{array}$ & $\begin{array}{c}68 \\
73 \\
0.93\end{array}$ & $\begin{array}{c}9,074 \\
9,074 \\
1.0\end{array}$ \\
\hline
\end{tabular}

The converse error of reporting false positives might be important in the study of influenza, which may well be confused with the common cold in epidemiological investigations. In general, the effect of this would be to reduce the value of the case:control ratio. It is therefore quite possible that the inclusion in our records of a number of cases of common cold could account in part for our lower relative risk estimates. That this is happening is borne out by the epidemic analysis above. On these grounds we feel that the revised estimate based solely on cases occurring in epidemic periods is altogether better justified.

\section{Discussion}

The remaining disparity between this figure of 1.79 and the five-fold cancer risk reported by Fedrick and Alberman (1972) may be a chance finding. Examination of the numbers of deaths from malignant disease of children born in the spring of 1958 shows that the week of the National Birthday Trust study is associated with a high mortality from leukaemia as compared with the adjoining weeks. Moreover, there are one or two unexplained peculiarities of the data, such as the unusually high onset ages of the leukaemia cases.

Associations between influenza incidence and subsequent cancer mortality may also be examined by relating the two sets of population rates-as indeed Fedrick and Alberman did on an annual basis. Current studies on the same lines but on a monthly basis again suggest that there was something atypical about the year 1958 and that the relative risk, if detectable over a long period at all by these methods, is much lower than has been suggested. Similar conclusions were reached by Leck and Steward (1972), who examined in relation to influenza epidemics the dates of birth of children registered by the Manchester Children's Tumour Registry. There are many difficulties with this type of analysis, however, not the least of which is that the association might be masked by fetal or perinatal deaths due to the influenza. (See Griffith et al. (1972) for a discussion of the relation between influenza prevalence and infant mortality.)

The possibility has been suggested that influenza itself is not associated with malignancy but rather that there is an unknown virus which is mistaken for influenza. This suggestion borders on the logically irrefutable, but it seems implausible in the light of the epidemic analysis above; for unless the prevalence of the unknown virus closely followed that of influenza-in particular appearing in the same epidemic years-one would expect to find a larger case-control excess outside the influenza epidemic periods, which is the reverse of what actually happens.

The assessment of the influenza risk is encumbered by several difficulties, most of which result from a general absence of definitive diagnosis. The same problem does not arise with varicella. It is known that the virus can cross the placenta and cause a number of congenital defects (Juel-Jensen and MacCallum, 1972), and it seems reasonable to conclude from our study that it has been directly involved in the development of malignancies. The negative findings associated with herpes zoster could be due to the fact that there is usually no viraemia with this manifestation of the infection.

When assessing the evidence as a whole it is important to remember that influenza, chickenpox, and rubella have been selected out of a number of virus infections as being the most noteworthy. The total number of different infections, however, is not large, and it is difficult to ignore the possibility that certain viruses invading the mother are capable of initiating malignancy in the fetus. The long-term significance of this and the possibility of common factors between the viruses involved remain to be seen.

Meanwhile, we feel that it is important to emphasize that these findings are mainly of scientific interest and that the numbers of children dying of malignant disease as a result of maternal virus infections are extremely small.

We wish to thank Dr. Alice Stewart for her help in the preparation of this paper.

The Oxford Survey of Childhood Cancers is now carried out in co-operation with the Marie Curie Memorial Foundation and is also supported by grants from the U.S. Public Health Service (grant No. CA-05392 and contract No. FDA 72-126), the Medical Research Council (grant No. G.964/230/C), and the Lawson Tait Research Trust.

The data were collected by a nation-wide network of survey doctors working on behalf of county and county borough health departments.

Requests for reprints should be addressed to: Mr. G. J. Draper, Department of Social Medicine, 8 Keble Road, Oxford OX1 3QN.

\section{References}

Adelstein, A. M., and Donovan, J. W. (1972). British Medical fournal, 4,

Fedrick, J., and Alberman, E. D. (1972). British Medical Fournal, 2, 485.

Griffith, G. W., Adelstein, A. M., Lambert, P. M., and Weatherall, J. A. C. (1972). British Medical fournal, 3, 553.

Juel-Jensen, B. E., and MacCallum, F. O. (1972). Herpes Simplex Varicella and Zoster. London, Heinemann.

Leck, I., and Steward, J. K. (1972). British Medical fournal, 4, 631.

Miettinen, O. S. (1970). Biometrics, 26, 75.

Purtilc, D., Hallgren, H., and Yunis, E. (1972). Lancet, 1, 769.

Stewart, A. M., Webb, J., and Hewitt, D. (1958). British Medical fournal, $1,1495$.

Stuart-Harris, C. H. (1965). Influenza and Other Virus Infections of the Respiratory Tract. London, Arnold. 